\title{
TROPICAL ORCHID MYCORRHIZAE: POTENTIAL APPLICATIONS IN ORCHID CONSERVATION, COMMERCIALIZATION, AND BEYOND
}

\author{
Joel Tupac Otero ${ }^{1,2^{*}}$, Ana Teresa Mosquera ${ }^{3} \&$ Nicola S. Flanagan ${ }^{3}$ \\ ${ }^{1}$ Departamento de Ciencias Biológicas, Universidad Nacional de Colombia sede Palmira, Cra 32 12-00, \\ Palmira, Valle del Cauca, Caolombia \\ ${ }^{2}$ Instituto de Estudios Ambientales IDEA, Universidad Nacional de Colombia sede Palmira, Colombia \\ ${ }^{3}$ Programa de Biología, Pontificia Universidad Javeriana, Cali, Colombia \\ *Author for correspondence: jtoteroo@unal.edu.co
}

\begin{abstract}
AвSTRACT. Orchid mycorrhizae are unique interactions in the plant kingdom involving all the orchids and a variety of fungi including Rhizoctonia. Orchids are one of the most charismatic plant families and include at least 20,000 species widely appreciated by specialist growers and scientists. They also include Vanilla, source of one of the most traded spices worldwide. Most mycorrhizal fungi belong to a group of basidiomycetes widely known for their pathogenic interaction with many crop plants including potatoes, rice, and beans. The main application of orchid mycorrhizal fungi is in the propagation of endangered and commercial orchid species, but we have recently documented an alternative use. The fungal symbionts of orchids have the ability to induce resistance to Rhizoctonia in rice plants, which opens new possibilities of biological control agents never previously imagined.
\end{abstract}

KEY WORDS: mycorrhiza, fungi, Orchidaceae, Rhizoctonia, biological control

Comprising $10 \%$ of angiosperm species, Orchidaceae contains an estimated 25,000 different species (Dressler 1993). Within Ecuador, 3784 orchid species are reported, with 3264 species in neighboring Colombia (Dodson 2003). The high diversity of Orchidaceae in these countries reflects the presence of two biodiversity hotspots in the northwestern region of South America: the tropical Andean region and the Chocó-Darien biodiversity hotspot (Myers et al. 2002).

Orchids have attracted considerable scientific interest since Darwin's seminal publication (1877). Unfortunately, the fascinating and diverse floral morphology of orchids has also led in recent decades to serious threats to the survival of many orchid species. Particularly in regions with weak law-enforcement, considerable pressure is exerted on natural orchid populations from unsustainable extraction of specimens from their natural populations for commercialization. The value of ornamental trade in orchids has been estimated at US \$2 billion annually (Harron et al. 2007). The ornamental orchid market in Taiwan alone was reported to be valued at US $\$ 114$ million in 2012. Although the Taiwan industry is largely based on Phalaenopsis species, breeders in that and other countries grow and export species native to the Neotropics. Orchid commercialization is also a growing industry in Neotropical countries. While many, if not most, orchid commercialization ventures are based on the sustainable propagation of plants ex situ, the novelty value of rare endemic species (which are often difficult or impossible to cultivate) means these species are subjected to continuing collection pressures. Additionally, currently non-commercialized species may provide valuable genetic resources in the development of novel commercial hybrids. It is not without reason that the whole of Orchidaceae with the exception of artificially propagated hybrids in the genera Cymbidium, Dendrobium, Phalaenopsis, and Vanda has been placed on Appendix II of the Convention on International Trade in Endangered Species of Wild Fauna \& Flora (CITES), which lists species that are not necessarily now threatened with extinction but that may become so unless trade is closely controlled.

Compounding the negative impact of wild specimen collection on orchid populations is the fact that many orchid species tend to be rare in the wild, often with small, hyper-dispersed populations. This is particularly true for epiphytic species, which comprise 
an estimated $70 \%$ of all orchid species (Zotz, in press), with the great majority of these species occurring in tropical regions. In addition to extraction pressures, many orchid populations also face challenges to their survival from habitat destruction and ecosystem degradation, effects that are likely to be exacerbated as a consequence of their specialized interactions with pollinators, phorophytes, and mycorrhizal fungi. Furthermore, a recent study indicates that other, as yet unidentified factors related to microhabitat conditions may be limiting orchid distribution and abundances (McCormick et al. 2012). There is clearly much we still have to learn regarding orchid biology in natural habitats, in particular for tropical species, in order to understand the evolutionary processes underlying the high species diversity in this plant family and also identify factors that determine distributions and abundances of orchids in the wild so as to develop effective conservation strategies for them.

The combination of commercial interest in tropical orchids and the rapid rate of ecosystem degradation in tropical regions has led to dramatic declines in many orchid populations (Seaton 2007). Among many conservation measures that need to be implemented, key requisites for ensuring orchid population survival are the maintenance of the levels of recruitment of individuals into established populations as well as the restoration of orchid populations in suitable sites.

Orchid research has principally focused on taxonomy and the role played by pollination biology in diversification (Micheneau et al. 2009; Schiestl \& Schluter 2009). However, other aspects of their biology, in particular their mycorrhizal interactions, are increasingly gaining prominence in the scientific literature (e.g. Rasmussen 1995; Dearnaley 2007; Kottke \& Suarez 2009; Hossain et al. 2013). In addition to the specialized relationships orchids often have with their pollinators, accumulating studies have revealed that some epiphytic orchids may also have strong preferences for their host tree (phorophyte) as well as their associated mycorrhizal fungi. Clear examples of orchid distributions being limited with respect to phorophyte have been reported (e.g. Gowland et al. 2007, 2013; Crain 2012). Varying degrees of mycorrhizal specificity have been observed throughout Orchidaceae (Kottke et al. 2009; Yuang et al. 2010; Valadares et al. 2012), in particular in achlorophyllous species (Taylor \& Bruns 1997; Selosse \& Roy 2009). In tropical taxa, studies of epiphytic orchids in Oncidiinae have also revealed moderate to high levels of preference for specific clades of Ceratobasidium spp. (Otero et al. 2002, 2004, 2007; Valadares et al. 2012). More recently, Martos et al. (2012) showed a general pattern for different fungal preferences among orchids with terrestrial and epiphytic habits on the island of Réunion.

Although historically the greater focus has been placed on orchid pollination biology, it is likely that seedling establishment, rather than seed set, is the limiting step in orchid life cycles (Calvo 1993; Otero \& Flanagan 2006; Tremblay \& Otero 2009). One pollination event will yield millions of seeds that are generally wind-dispersed. Seed germination and seedling establishment, in contrast, may be more challenging for the orchid plant. Lacking endosperm, orchid seeds have minimal energy resources for germination and rely instead upon mycorrhizal symbioses to provide carbon and nutrients (Bidartondo et al. 2004; Selosse \& Roy 2009). Thus the availability of a suitable mycorrhizal fungus is crucial to orchid establishment in the wild, and studies of orchid mycorrhizae across the family have yielded a complicated panorama of orchid mycorrhizal associations with varying degrees of specificity to one or several different fungal taxa (e.g. Otero et al. 2002; Martos et al. 2012).

Orchid mycorrhizal interactions also occur in adult plants. In photosynthetic plants it has been generally assumed that the provision of carbon to the plant from the fungus is not essential, yet it seems that mixotrophic nutritional strategies, in which the plant receives carbon from both photosynthesis and mycorrhizal interaction, are common (Selosse \& Roy 2009; Roy et al. 2013). In this case it may be that different parts of the plant receive carbon provision from both sources. There is some indication that those fungi involved in seed germination are not the same as those that associate with adult plants. In tests of seed germination efficiency of different fungal isolates from adult plants, fungi with provenance from other species were sometimes more efficient (Otero et al. 2004; Porras \& Bayman, 2007).

Generally, mycorrhizal fungi in orchids belong to the Rhizoctonia-like Basidiomycetes (Bayman 
\& Otero 2006), but recent studies have shown that other groups of fungi can be involved. For example, members of the Basidiomycete 'rust' lineage (Atractiellomycetes, Pucciniomycotina) are mycobionts of orchids (Kottke et al. 2009). Epipactis microphylla (Ehrh.) Sw. (Neottieae, Orchidaceae) is associated with Ascomycete fungal species allied to the ectomycorrhizal Septomycetes, including truffles (Selosse et al. 2004).

Rhizoctonia-like fungi may be characterized by certain hyphal morphological traits, including: a lack of conidia; the hyphal branch at a right angle; a septum located a short distance from a constricted ramification; and presence of monilioid cells, a special type of cell with a rounder shape, mainly in sclerotic structures (Roberts 1999). The young hyphae can be multi- or binucleate and rarely produce fruiting bodies in culture, making it difficult to distinguish different species from anamorph (asexual) cultures. The teleomorph (sexual stage) of Rhizoctonia can be Ceratobasidium, Thanatephorus (multinucleate), Tulasnella or Sebacina, which differ morphologically (Roberts 1999). However, it has proved extremely difficult to promote sexual stages from asexual cultures under laboratory conditions. The Rhizoctonia-like fungi are grouped into anastomosis groups (AG) based on their capacity for hyphal fusion. Multinucleate Rhizoctonia (Thanatephorus) have 13 AG (AG1AG13), and binucleate Rhizoctonia (Ceratobasidium, Tulasnella, and Sebacina) have been divided in 15 groups (AG-A to AG-O) (Sneh et al. 1991). Despite these known traits, fine-scale characterization of fungal strains based on morphological characters has been a major obstacle to understanding orchid mycorrhizal interactions.

Over the last decade or so, DNA sequence data have been successfully applied to identify different fungal species from pure fungal cultures or even directly from fungal tissue present in the roots of adult plants (Otero et al. 2002, 2004, 2005, 2007, 2011; Pereira et al. 2003, 2005, 2009; Suarez et al. 2008, 2009; Valadares 2012; Mosquera et al. 2013). The most frequent gene region sequenced for the Rhizoctonia-like fungi identification has been the internal transcribed spacer (ITS) of ribosomal DNA. In tropical orchids, four separate Ceratobasidium clades were reported from epiphytic Oncidiinae in Puerto Rico (Otero et al. 2002, 2004, 2005) and Central America (Otero et al. 2007). Three further related clades have been found in the Brazilian Coppensia doniana (Bateman ex W.H.Baxter) Campacci (Oncidiinae), now correctly known as Gomesa doniana (Bateman ex. W.H.Baxter) M.W.Chase \& N.H.Williams (Valadares et al. 2012). Another occurs in Notylia (Oncidiinae), Habenaria (Orchidinae), Cranichis (Cranichidinae), Vanilla (Vanillinae), Epidendrum xanthinum Lindl. (Laeliinae), Trizeuxis falcata Lindl. (Oncidiinae), Maxillaria (Maxillariinae), and Dichaea (Dichaeinae) (Mosquera et al. 2010). These Ceratobasidium clades associated with Neotropical orchids are not too distantly related to the fungi that are associated with Pterostylis (Pterostylidinae) in temperate southeastern Australia (Otero et al. 2011). Fungi belonging to the teleomorph Tulasnella have also been isolated from species of Pleurothallidinae (Suarez et al. 2006) and Laeliinae (Pereira et al. 2001, 2005, 2006; Almeida et al. 2007), as well as members of Vanilla in Puerto Rico (Porras \& Bayman, 2007) and Colombia (MosqueraEspinosa et al., unpubl.).

These studies represent an important step forward for our understanding of the ecological interactions between tropical orchids and their mycorrhizal fungi at both the seed germination stage and in adults. However, the finding of differing patterns of mycorrhizal associations within the small number of tropical orchid species studied so far indicates the importance of continuing exploration of the diversity and functional preferences of these symbioses across the large number of orchids native to northwestern South America. Clearly, those orchid species facing the greatest conservation threats, either from unsustainable extraction for commercialization or from habitat degradation should be prioritized for orchid mycorrhizal studies. Once the orchid mycorrhizal fungi (OMF) have been characterized, studies can then focus on their application in orchid conservation programs for symbiotic orchid propagation from seed for reintroduction and commercial purposes, as well as for other potential applications which we discuss below.

Commercially, there are two main orchid trades ornamental species and the cultivation of Vanilla. In both trades, symbiotic seed germination could provide considerable benefits. While many species may be 
propagated from seed asymbiotically or vegetatively in vitro, the presence of fungal mycorrhizae is likely to enhance orchid plant hardening and establishment success in reintroduction programs into the wild. During symbiotic germination trials, fungi that give a large advantage to seedling growth over asymbiotic procedures have been identified. However, this is not always straightforward. As mentioned above, fungi isolated from the adult of the species are not always the most effective at promoting seed germination in the same species (Otero \& Bayman 2009).

In Puerto Rico, seeds of both Tolumnia variegata (Sw.) Braem and Ionopsis utriculariodes (Sw.) Lindl. were symbiotically germinated using fungi isolated from adults of the same species (Otero et al. 2004, 2005). Similarly, seeds of four groups of species of Pterostylis s.l. were symbiotically germinated with their mycorrhizal fungi (Otero et al. 2011). The three Ceratorhiza and uninucleate Rhizoctonia anamorphs isolated from Coppensia doniana Bateman ex W.H.Baxter) Campacci [= Gomesa doniana (Bateman ex W. H.Baxter) M.W.Chase \& N.H.Williams] were also used successfully in the in vitro symbiotic germination of the same species (Valadares et al. 2012). However, Porras \& Bayman (2007) found that seeds of Vanilla species germinated better with a Ceratobasidium fungus isolated from Ionopsis utricularioides than from Tulasnella isolated from adult Vanilla plants. These findings indicate that considerable study may be needed in order to identify the most appropriate fungal partners for both orchid conservation and commercialization.

Additionally, biotechnological techniques need to be enhanced to improve efficiency of symbiotic germination and reduce possible contamination with other microorganisms. Bayman (2012) developed a formula for in-situ symbiotic propagation using calcium alginate and combining orchid seeds and mycorrhizal fungi for Epidendrum ibaguense Kunth to facilitate control of the fungal presence under natural conditions.

Vegetative propagation is almost universally used in Vanilla cultivation. However, Vanilla crops face serious threats from low genetic diversity, leading to increased sensitivity to crop pathogens; propagation from seed would help to promote genetic diversity. At the Universidad Nacional de Colombia, Palmira campus, Jazmin Alomia is inducing symbiotic germination of Vanilla calyculata Schltr. with a Rhizoctonia-like fungus (Alomía et al., unpubl.).

In addition to their functional role as orchid mycorrhizae, some Rhizoctonia-like fungi are also recognized as plant pathogenic fungi (Sneh et al. 1991; Roberts 1999). Rhizoctonia solani (teleomorph: Thanatephorus cucumeris) is pathogenic in many crop species with a worldwide distribution. It causes damping off in beetroot, potato, beans, soya, and cereals including rice and corn (Sneh et al. 1991) among others, including some of the most important crops in tropical regions.

The control of pathogenic Rhizoctonia-like fungi generally involves chemical and biological control as well as cultural practices. In recent years the use of biocontrol against pathogenic Rhizoctonia fungi of human food products has become more widespread as a means of limiting the use of synthetic agrochemicals that may be detrimental to both consumers and the environment. Ideally, a fungal biocontrol agent should specifically target the pathogenic fungus and not those that may be beneficial, such as mycorrhizal and pest pathogens. There are many examples of potential biological control of pathogenic Rhizoctonia using mycopathogenic fungi such as Trichoderma sp. and Chaetomium sp. (Gao et al. 2005). A hypovirulent Rhizoctonia-like fungus has been used to induce systemic resistance against pathogenic Rhizoctonia (Gressel 2001).

In our studies in Colombia, Rhizoctonia-like fungi were isolated from a number of different orchid species and evaluated for biocontrol potential against the pathogenic Rhizoctonia solani in rice (Mosquera et al. 2010). The orchid mycorrhizal fungi OMF were identified using ITS sequences and found to form four discrete groups. The first included fungi from tropical epiphytic orchids; the second included plant pathogenic Rhizoctonia species (Thanatephorus spp.) used as a positive control; the third included mycorrhizal fungi from terrestrial orchids; and the final group included mycorrhizal fungi from Vanilla species (Mosquera et al. 2013).

To evaluate whether the OMF were pathogenic on rice, isolates were inoculated on healthy plants in controlled glasshouse conditions designed to favor the pathogenicity of Rhizoctonia solani in rice 
(high humidity and temperature). The OMF induced some symptoms of pathogenicity in rice, but the severity was significantly lower that those induced by the positive Rhizoctonia solani control isolated from local rice plantations (Mosquera et al. 2013). However, when the effect on inducing resistance against pathogenic fungi was evaluated, those healthy rice plants inoculated with OMF two days before inoculation with the pathogenic fungi had significantly fewer pathogenicity symptoms than the control plants inoculated only with the pathogenic Rhizoctonia solani but without OMF (Mosquera et al. 2013). These findings show that non-pathogenic Rhizoctonia species that form mycorrhizae with tropical epiphytic orchids may have potential application as biocontrol agents. Further work is needed to understand the biological mechanism through which this effect is mediated and also to develop the technological application.

\section{Conclusions}

While the application of OMF in orchid propagation for research, conservation, and commercial purposes has been broadly recognized, the true potential of this application is still to be realized in Neotropical regions. Effective application of OMF for conservation and commercial purposes requires a considerable amount of a priori study in order to determine which combination of plant species and fungal partner is most effective.

Our studies in Colombia are now showing that OMF are potentially valuable biocontrol agents for important crop pathogens, thus providing another tool for reducing the application of agrochemicals on already sensitive tropical ecosystems. This deserves greater exploration and study over the coming years.

ACKNOWLEDGMENTS. We thank DIPAL and Hermes from Universidad Nacional de Colombia for support. ATM was supported by a fellowship from Colciencias "Doctorados Nacionales" 2006.

\section{Literature Cited}

Almeida, P.R.M., C. van der Berg \& A. Goes-Neto. 2007. Morphological and molecular characterization of species of Tulasnella (Homobasidiomycetes) associated with Neotropical plants of Laeliinae (Orchidaceae) occurring in Brazil. Lankesteriana 7: 22-27.
Bayman, P. 2012. Growing epiphytic orchids from seed: a simple, nonsterile, symbiotic method. Orchids 81: 564567.

Bayman, P. \& J.T. Otero. 2006. Microbial endophytes of orchid roots: diversity and effects on plants. P. 153-178 in: B. Schulz, C. Boyle \& T. Sieber (eds.), Microbial root endophytes. Soil biology 9. Springer-Verlag, Berlin, Germany.

Bidartondo, M.I., B. Burghardt, G. Gebauer, T.D. Bruns \& D.J. Read. 2004. Changing partners in the dark: isotopic and molecular evidence of ectomycorrhizal liaisons between forest orchids and trees. Proc. Roy. Soc. London B (Biol. Sci.) 271: 1799-1806.

Calvo, R.N. 1993. Evolutionary demography of orchids: intensity and frequency of pollination and the cost of fruiting. Ecol. 74: 1033-1042.

Crain, B. 2012. On the relationship between bryophyte cover and the distribution of Lepanthes spp. Lankesteriana 12: 13-18.

Dearnaley, J.D.W. 2007. Further advances in orchid mycorrhizal research. Mycorrhiza 17: 475-486.

Darwin, C. 1877. The various contrivances by which orchids are fertilized by insects. 2nd ed. John Murray, London.

Dodson, C. 2003. Why are there so many orchid species? Lankesteriana 7: 99-103.

Dressler, R.L. 1993. Phylogeny and classification of the orchid family. Dioscorides Press, Portland, Oregon.

Gao, H., N.N. Narayanan, L. Ellison \& M.K. Bhattacharyya. 2005. Two classes of highly similar coiled coilnucleotide binding-leucinerich repeat genes isolated from the Rps1-klocus encode Phytophthora resistance in soybean. Molec. Pl.-Microbe Interactions 18: 10351045.

Gowland, K.M, U. Mathesius, M.A. Clements \& A.B. Nicotra. 2007. Understanding the distribution of three species of epiphytic orchids in temperate Australian rain forest by investigation of their host and fungal associates. Lankesteriana 7: 44-46.

Gowland, K.M., M.M. van der Merwe, C.C. Linde, M.A. Clements \& A.B. Nicotra. 2013. The host bias of three epiphytic Aeridinae orchid species is reflected, but not explained, by mycorrhizal fungal associations. Amer. J. Bot. 100: 764-777.

Gressel, J. 2001. Potential failsafe mechanisms against the spread and introgression of transgenic hypervirulent biocontrol fungi. Trends Biotechnol. 19: 149-154.

Harron, M., M. Nasir Shamsudin, I. Latif \& F. Repin. 2007. Bio-tech orchid: wealth creation and entrepreneurial development. J. ISSAAS [International Society for Southeast Asian Agricultural Sciences] (Dec 2007). http:// agris.fao.org/agris-search/search/display.do?f=2012/PH/ PH1201.xml;PH2011000446 (visited Nov. 2012).

Hossain, M.M., R. Kant, P.T. Van, B. Winarto, S. Zeng \& J.A. 
Teixeira da Silva. 2013. The application of biotechnology to orchids. Critical Rev. P1. Sci. 32: 69-139.

Kottke I. \& J.P. Suárez. 2009. Mutualistic, root-inhabiting fungi of orchids - identification and functional types. Pp. 84-99 in: A.M. Pridgeon \& J.P. Suárez (eds.), Proceedings of the Second Scientific Conference on Andean Orchids. Universidad Técnica Particular de Loja, Loja, Ecuador.

Kottke, I., J.P. Suárez, P. Herrera, D. Cruz, R. Bauer, I. Haug \& S. Garnica. 2009. Atractiellomycetes belonging to the 'rust' lineage (Pucciniomycotina) form mycorrhizae with terrestrial and epiphytic neotropical orchids. Proc. Roy. Soc. B (Biol. Sci.) 277: 1289-1298.

Martos, F., F. Munoz, T. Pailler, I. Kottke, C. Gonneau \& M.A. Selosse. 2012. The role of epiphytism in architecture and evolutionary constraint within mycorrhizal networks of tropical orchids. Molec. Ecol. 21: 5098-5109.

McCormick, M.K, L.D. Taylor, K. Juhaszova, R.K. Burnett, D.F. Whigham \& J.P. O’Neill. 2012. Limitations on orchid recruitment: not a simple picture. Molec. Ecol. 21: 1511-1523.

Micheneau, C., S. Johnson \& M.F. Fay. 2009. Orchid pollination: from Darwin to the present day. Bot. J. Linn. Soc. 161: 1-19.

Molineros, F.H. 2012. Recursos geneticos de Vanilla del hotspot de biodiversidad del Chocó en la Costa Pacífica Colombiana. Tesis de Maestría en recursos fitogeneticos neotropicales. Universidad Nacional de Colombia, Sede Palmira.

Mosquera-Espinosa, A.T., P. Bayman \& J.T. Otero. 2010. Ceratobasidium como hongo micorrízico de orquídeas en Colombia. Acta Agronom. 59: 316-326.

Mosquera-Espinosa, A.T., P. Bayman P., G.A. Prado, A. Gomez-Carabali \& J.T.Otero. 2013. Pathogenicity of orchid mycorrhizal fungi (Ceratobasidium sp.) on rice and biocontrol of Rhizoctonia solani sheath blight. Mycologia 105: 141-150.

Myers, N., R.A Mittermeier, C.G. Mittermeier, G.A.B. da Fonseca \& J. Kent. 2000. Biodiversity hotspots for conservation priorities. Nature 403: 853-858.

Otero, J.T., J.D. Ackerman \& P. Bayman. 2002. Diversity and host specificity of mycorrhizal fungi from tropical orchids. Amer. J. Bot. 89: 1852-1858.

Otero, J.T., J.D. Ackerman \& P. Bayman. 2004. Differences in mycorrhizal specificity between two tropical orchids. Molec. Ecol. 13: 2393-2404.

Otero J.T. \& P. Bayman. 2009. Symbiotic vs. asymbiotic seed germination in epiphytic orchids. Acta Agronom. 58: 270-276.

Otero, J.T., P. Bayman \& J.D. Ackerman. 2005. Individual variation in plant and fungus for mycorrhizal seed germination in an epiphytic orchid. Evol. Ecol. 19: 29-43.
Otero, J.T. \& N.S. Flanagan. 2006. Orchid diversity: beyond deception. Trends Ecol. Evol. 21: 64-5.

Otero J.T., N.S. Flanagan, E.A. Herre, J.D. Ackerman \& P. Bayman. 2007. Widespread mycorrhizal specificity correlates to mycorrhizal function in the neotropical, epiphytic orchid, Ionopsis utricularioides (Orchidaceae). Amer. J. Bot. 94: 1944-1950.

Otero, J.T., P.H. Thrall, M.A. Clements, J.T. Miller \& J.J. Burdon. 2011. Co-diversification of orchids (Pterostylidinae) and their associated mycorrhizal fungi. Austral. J. Bot. 59: 480-497.

Pereira, M.C. 2006. Diversidade e especificidade de fungos micorrízicos de orquídeas asociados a Epidendrum secundum em um campo de altitude no Parque Estadual da Serra do Brigadeiro-MG. MSc dissertation, Universidade Federal de Vicosa, Vicosa, Brazil.

Pereira, O.L. 2001. Caracterizacao morfológica e molecular de fungos micorrízicos de sete especies de orquídeas neotropicais. MSc dissertation, Universidade Federal de Vicosa, Vicosa, Brazil.

Pereira, O.L., M.C.M. Kasuya, C.L. Rollemberg \& A.C. Borges. 2005. Inducao in vitro da germinacao de sementes de Coppensia doniana por fungos micorrízicos rizoctonióides. R. Bras. Ci. Solo 29: 199-206.

Pereira, M.C., O.L. Pereira, M.D. Costa, R.B. Rocha \& M.C.M. Kasuya. 2009. Diversity of mycorrhizal fungi Epulorhiza spp. isolated from Epidendrum secundum (Orchidaceae). R. Bras. Ci. Solo 33: 118-1197.

Pereira, O.L., C.L. Rollemberg, A.C. Borges, K. Matsuoka \& M.C.M. Kasuya. 2003. Epulorhiza epiphytica sp. nov. isolated from mycorrhizal roots of epiphytic orchids in Brazil. Mycoscience 44: 153-155.

Porras-Alfaro, A. \& P. Bayman. 2007. Mycorrhizal fungi of Vanilla: diversity, specificity and effects on seed germination and plant growth. Mycologia 99: 510-525.

Rasmussen, H.N. 1995. Terrestrial orchids: from seed to mycotrophic plant. Cambridge University Press, Cambridge, U.K.

Roberts, P. 1999. Rhizoctonia-forming fungi: a taxonomic guide. Royal Botanical Gardens, Kew.

Roy, M., C. Gonneau, A. Rocheteau, D. Berveiller, J.-C. Thomas, C. Damesin \& M.-A. Selosse. 2013. Why do mixotrophic plants stay green? A comparison between green and achlorophyllous orchid individuals in situ. Ecol. Monogr. 83: 95-117.

Seaton, P.T. 2007. Orchid conservation: where do we go from here? Lankesteriana 7: 13-16.

Schiestl, F.P. \& P.M. Schlüter. 2009. Floral isolation, specialized pollination, and pollinator behavior in orchids. Ann. Rev. Entomol. 54:425-446.

Selosse, M.A., A. Faccio, G. Scappaticci \& P. Bonfante. 2004. Chlorophyllous and achlorophyllous specimens of Epipactis microphylla (Neottieae, Orchidaceae) 
are associated with ectomycorrhizal Septomycetes, including truffles. Microbial Ecol. 47: 416-426.

Selosse, M.A. \& M. Roy. 2009. Green plants that feed on fungi: facts and questions about mixotrophy. Trends P1. Sci. 14: 64-70.

Sneh, B., L. Burpee \& A. Ogoshi. 1991. Identification of Rhizoctonia species. American Phytopathological Society, St Paul. Minnesota.

Suárez, J.P., M. Weiß, A. Abele, S. Garnica, F. Oberwinkler \& I. Kottke. 2006. Diverse tulasnelloid fungi form mycorrhizas with epiphytic orchids in an Andean cloud forest. Mycol. Res. 110: 1257-1270.

Suárez, J.P., M. Weiß, A. Abele, F. Oberwinkler \& I. Kottke. 2008. Members of Sebacinales subgroup B form mycorrhizae with epiphytic orchids in a neotropical mountain rain forest. Mycol. Progress 7: 75-85.

Suárez J.P., M. Weiß, A. Abele, F. Oberwinkler \& I. Kottke. 2009. Epiphytic orchids in a mountain rain forest in southern Ecuador harbor groups of mycorrhizaforming Tulasnellales and Sebacinales subgroup B (Basidiomycota). Pp. 184-196 in: A.M.Pridgeon \& J.P. Súarez (eds.), Proceedings of the Second Scientific
Conference on Andean Orchids. Universidad Técnica Particular de Loja, Loja, Ecuador.

Taylor, D.L. \& T.D. Bruns. 1997. Independent, specialized invasions of ectomycorrhizal mutualism by two nonphotosynthetic orchids. Proc. National Acad. Sci., USA, 94: 4510-4515.

Tremblay, R. \& J.T. Otero. 2009. Orchid conservation biology: predicting species dynamics and community interactions. Pp. 197-207 in: A.M. Pridgeon A.M. \& J.P. Suarez (eds.), Proceedings of the Second Scientific Conference on Andean Orchids. Universidad Técnica Particular de Loja, Loja, Ecuador.

Valadares, R.B.S., M.C. Pereira, J.T. Otero \& E.J.B.N. Cardoso. 2011. Orchid mycorrhizal diversity in Coppensia doniana, a widespread Oncidiinae from Campos do Jordão-SP, Brazil. Biotropica 44: 114-122.

Yuan, L., Yang Z.L., S-Y. Li, H. Hu \& H. Jia-Lin. 2010. Mycorrhizal specificity, preference, and plasticity of six slipper orchids from South Western China. Mycorrhiza 20: 559-568.

Zotz, G. In press. The systematic distribution of vascular epiphytes - a critical update. Bot. J. Linn. Soc. 